\title{
Suspended microstructures of epoxy based photoresists fabricated with UV photolithography
}

Hemanth, Suhith; Anhøj, Thomas Aarøe; Caviglia, Claudia; Keller, Stephan Sylvest

Published in:

Microelectronic Engineering

Link to article, DOI:

10.1016/j.mee.2017.01.026

Publication date:

2017

Document Version

Peer reviewed version

Link back to DTU Orbit

Citation (APA):

Hemanth, S., Anhøj, T. A., Caviglia, C., \& Keller, S. S. (2017). Suspended microstructures of epoxy based photoresists fabricated with UV photolithography. Microelectronic Engineering, 176, 40-44.

https://doi.org/10.1016/j.mee.2017.01.026

\section{General rights}

Copyright and moral rights for the publications made accessible in the public portal are retained by the authors and/or other copyright owners and it is a condition of accessing publications that users recognise and abide by the legal requirements associated with these rights.

- Users may download and print one copy of any publication from the public portal for the purpose of private study or research.

- You may not further distribute the material or use it for any profit-making activity or commercial gain

- You may freely distribute the URL identifying the publication in the public portal 


\title{
Suspended Microstructures of Epoxy Based Photoresists Fabricated with UV Photolithography
}

\author{
Suhith Hemanth ${ }^{a}$, Thomas A. Anh $\varnothing \mathbf{j}^{b}$, Claudia Caviglia ${ }^{a}$ and Stephan S. Keller ${ }^{a}$ \\ ${ }^{a}$ Department of Micro- and Nanotechnology, DTU Nanotech, 2800 Kongens Lyngby, Denmark \\ ${ }^{b}$ DTU Danchip, 2800 Kongens Lyngby, Denmark \\ suhem@nanotech.dtu.dk
}

\begin{abstract}
In this work we present an easy, fast, reliable and low cost microfabrication technique for fabricating suspended microstructures of epoxy based photoresists with UV photolithography. Two different fabrication processes with epoxy based resins (SU-8 and $m r-D W L$ ) using UV exposures at wavelengths of $313 \mathrm{~nm}$ and $405 \mathrm{~nm}$ were optimized and compared in terms of structural stability, control of suspended layer thickness and resolution limits. A novel fabrication process combining the two photoresists SU-8 and $\mathrm{mr}$ DWL with two UV exposures at $365 \mathrm{~nm}$ and $405 \mathrm{~nm}$ respectively provided a wider processing window for definition of well-defined suspended microstructures with lateral dimensions down to $5 \mu \mathrm{m}$ when compared to $313 \mathrm{~nm}$ or $365 \mathrm{~nm}$ UV photolithography processes.
\end{abstract}

\section{Introduction}

The epoxy-based photoresist SU-8 is well established for the microfabrication of 3D microstructures for various applications such as tissue engineering, microelectromechanical systems (MEMS) and microfluidics [1]-[6]. Furthermore SU-8 is also the most common polymer template for the fabrication of pyrolytic carbon electrodes using the Carbon MEMS (C-MEMS) process [7]. The resist allows fabrication of high aspect ratio microstructures with high mechanical and chemical stability using standard UV photolithography due to the low absorption of UV wavelengths above $350 \mathrm{~nm}$ [8]. At the same time, the low UV absorption results in challenges for fabrication of overhanging or suspended features by subsequent steps of SU-8 photolithography. In the past, different fabrication processes have been proposed for the fabrication of suspended 3D SU-8 microstructures. Advanced methods such as X-ray, e-beam and two-photon lithography have been proposed for fabrication of high resolution 3D microstructures [9]-[12]. The limiting factor for these techniques is the low throughput.

Alternatively, several approaches using UV photolithography have been introduced. The most common process involves adding a polymerization-stop-layer between the structures to be suspended and the substrate [13], [14]. Alternatively lamination of a polymer foil on top of a patterned template followed by 
patterning of the foil has been proposed [15], [16]. The complexity of these fabrication processes increases as the structures become multi-layered (i.e. more 3D). Another method includes doping of SU-8 with nanoparticles or tailoring of the photoinitiator concentration to control the thickness of suspended layers. However adding nanoparticles such as $\mathrm{Fe}_{2} \mathrm{O}_{3}$ or increasing the concentration of photoinitiator requires an additional preparation step [17], [18]. Furthermore, suspended macrostructures have been fabricated with grayscale photolithography, but without achieving micron or submicron resolution [7].

Recently, fabrication of suspended SU-8 layers by partial exposure at a wavelength of $365 \mathrm{~nm}$ has been demonstrated [19]-[21]. The limiting factor of this fabrication process is the narrow processing window ( $5 \pm 1$ sec UV exposure) for the partial exposure [22]. We observed that minor variations in parameters such as the baking temperature, humidity and exposure dose resulted in cracks and difficulties to control the suspended layer thickness (Figure 1.A). Furthermore, instability of the features with a size smaller than $10 \mu \mathrm{m}$ was seen (Figure 1.B). Alternatively, the use of a lower wavelength (313 $\mathrm{nm}$ ) to crosslink or pattern the suspended layer has been proposed [14]. At this wavelength, the absorption by the $\mathrm{SU}-8$ is increased resulting in lower penetration depth of the UV radiation.

In this work, we introduce a third approach for fabrication of suspended layers of epoxy based photoresists with UV photolithography using a higher wavelength of $405 \mathrm{~nm}$. The combination of two different photoresists (SU-8 and mr$D W L$ ) is exploited to fabricate suspended layers
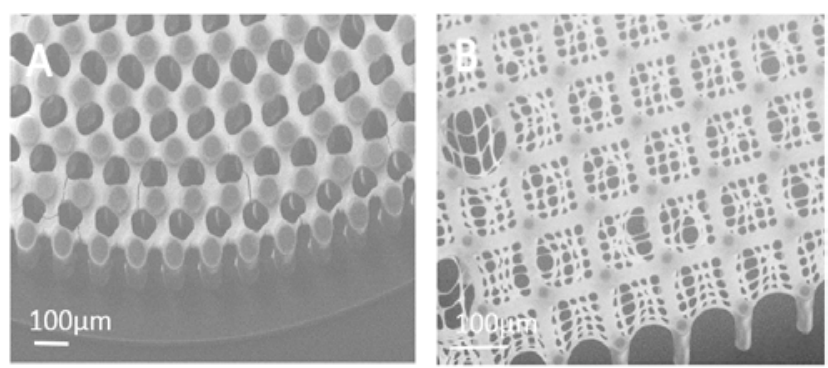

Figure 1: Defects in suspended SU-8 layer fabricated with $365 \mathrm{~nm}$ partial UV exposure according to [22] (A) Cracks on the suspended layer (B) Unstable suspended SU-8 microstructures

with a precise lateral and longitudinal resolution. The novel approach is compared with a process using partial exposure at wavelengths of $313 \mathrm{~nm}$ to crosslink the suspended layers. Compared to earlier work, all the processes were carried out with a low temperature baking profile to minimize the thermal stress [23], [24]. After optimization of the exposure dose, both fabrication processes result in a well-defined suspended layer in lateral direction. However, the fabrication process with $405 \mathrm{~nm}$ and mr-DWL provides a wider processing window and improved control of the thickness of the suspended layer.

\section{Methods}

\section{1. $313 \mathrm{~nm}$ UV photolithography}

The fabrication of suspended microstructures using $313 \mathrm{~nm}$ photolithography is illustrated in Figure 2. Approximately $5 \mathrm{ml}$ of SU-8 2075 (MicroChem, USA) were manually dispensed on a 4-inch $\mathrm{Si} / \mathrm{SiO}_{2}$ substrate and coating was performed using a two-step spin process on a RCD8 T spin-coater (Süss Micro-Tec, Germany). A spread cycle of $30 \mathrm{~s}$ at $700 \mathrm{rpm}$ with $100 \mathrm{rpms}^{-1}$ acceleration was applied, followed 
by a thinning cycle at $1600 \mathrm{rpm}$ for $60 \mathrm{~s}$ with 100 rpms $^{-1}$ acceleration yielding a uniform $98 \mu \mathrm{m}$ thick film. The edge bead was removed by dispensing propylene glycol methyl ether acetate (PGMEA) at the edge of the rotating wafer at $300 \mathrm{rpm}$ for 30 secs (Figure 2.A). To minimize the thermal stress low temperature baking steps were used [24]. The wafers were placed on a programmable hotplate (Harry Gestigkeit $\mathrm{GmbH}$, Germany) at room temperature and ramped to $50{ }^{\circ} \mathrm{C}$ at $2{ }^{\circ} \mathrm{Cmin}^{-1}$ followed by a soft bake (SB) for $5 \mathrm{~h}$ at $50^{\circ} \mathrm{C}$ and natural cooling for $2 \mathrm{~h}$. The SU-8 layer was patterned by UV exposure on an EVG620 aligner (EVGroup, Austria) equipped with a mercury lamp and a long pass filter (SU-8 filter), adjusted to a constant intensity of $7 \mathrm{mWcm}^{-2}$ at $365 \mathrm{~nm}$ in soft contact mode through a mask. The intensity was measured with a UV-Optometer (SUSS UV-Optometer, SÜSS MicroTec AG, Germany) using a probe 365/405 channel 365, which is sensitive between $345 \mathrm{~nm}$ and $385 \mathrm{~nm}$, where $365 \mathrm{~nm}$ intensity is the maximum for a mercury lamp. The SU-8 filter blocks all wavelengths below $345 \mathrm{~nm}$. The mask $\left(M_{1}\right)$ includes designs of micropillar arrays with various pillar diameters $(\mathrm{d}=10-50 \mu \mathrm{m})$ with a varying pitch $(a=25-250 \mu \mathrm{m})$. The first UV exposure with a dose $D_{1}=210 \mathrm{mJcm}^{-2}$ (Figure 2.B) was followed by a second partial UV exposure at $313 \mathrm{~nm}$ with dose $D_{313}$ through a second mask $\left(M_{2}\right)$. For the partial exposure, the filter was changed to a $313 \mathrm{~nm}(250 \mathrm{~nm}$ to $350 \mathrm{~nm}$ ) short pass filter. A constant intensity of $1.05 \mathrm{mWcm}^{-2}$ was measured with a UVOptometer using a $320 \mathrm{~nm}$ probe which is sensitive between $290 \mathrm{~nm}$ and $345 \mathrm{~nm}$ including the predominate line for a mercury lamp at $313 \mathrm{~nm}$. The partial exposure dose $D_{313}$ was optimized to obtain well resolved microstructures on the suspended layer connecting the pillars (Figure 2.C). The mask
$\left(\mathrm{M}_{2}\right)$ includes distribution of holes with diameters $(w=10 \mu \mathrm{m}-50 \mu \mathrm{m})$ and varying pitch $(y=5 \mu \mathrm{m}-200 \mu \mathrm{m})$ which defines the suspended layer. For the post exposure bake (PEB), a baking temperature of $50^{\circ} \mathrm{C}$ for $5 \mathrm{~h}$ with a ramp of $2{ }^{\circ} \mathrm{Cmin}^{-1}$ followed by a natural cooling down to room temperature was used. The development in PGMEA was performed in two steps of $10 \mathrm{~min}$ followed by rinsing in isopropanol for $30 \mathrm{~s}$ and drying in air (Figure 2.D).

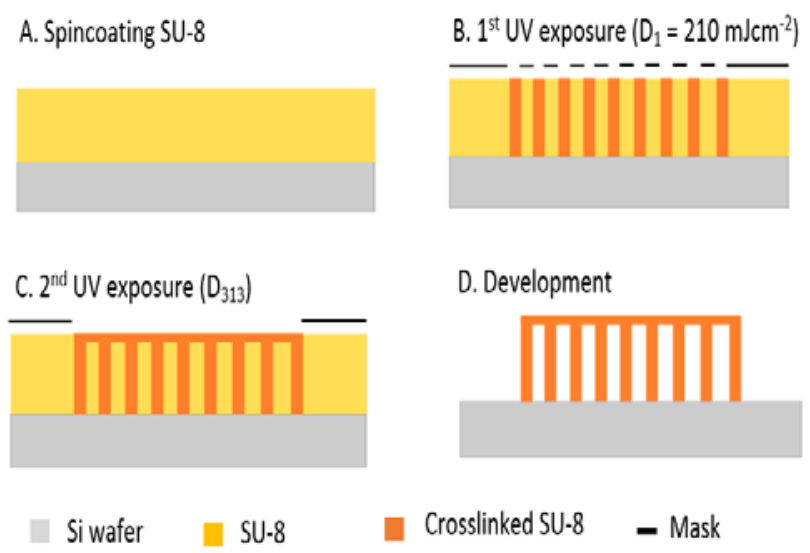

Figure 2 : Schematic of the $313 \mathrm{~nm}$ UV lithography process: (A) SU-8 is spin coated on a $\mathrm{Si} / \mathrm{SiO}_{2}$ substrate and soft-baked; (B) $1^{\text {st }} U V$ exposure at $365 \mathrm{~nm}$; (C) $2^{\text {nd }}$ partial UV exposure at $313 \mathrm{~nm}$ and post-exposure bake; (D) Development in PGMEA

\section{2. $405 \mathrm{~nm}$ UV photolithography}

The fabrication of suspended microstructures with $405 \mathrm{~nm}$ UV photolithography is shown in Figure 3. The supporting SU-8 pillars were fabricated as described in section 2.1 (Figure 3.A and $\mathrm{B}$ ). After the first SU-8 exposure (Figure 3.B), approximately $5 \mathrm{ml}$ of $\mathrm{mr}-\mathrm{DWL} \quad 40$ (Microresist technology $\mathrm{GmbH}$, Germany) were spin coated on the SU-8 at $4000 \mathrm{rpm}$ for $60 \mathrm{~s}$ with 100 rpms $^{-1}$ acceleration yielding a uniform $17 \mu \mathrm{m}$ thick film. The polymer stack was SB at $50{ }^{\circ} \mathrm{C}$ for $1 \mathrm{~h}$ (Figure 3.C). The aligner was equipped with two filters: The $365 \mathrm{~nm}$ broad 
band filter described above (SU-8 filter) and a $10 \mathrm{~mm}$ thick PMMA sheet (SPMMA0050NR00, NordiskPlast, Denmark) mainly to filter out the i-line at $365 \mathrm{~nm}$ wavelength. With this configuration the constant intensities at $313 \mathrm{~nm}, 365 \mathrm{~nm}$ and $405 \mathrm{~nm}$ were $0 \mathrm{mWcm}^{-2}$, $0.33 \mathrm{mWcm}^{-2}$ and $10.50 \mathrm{mWcm}^{-2}$ respectively. The intensity at $405 \mathrm{~nm}$ was measured with the UV-Optometer using probe 365/405 channel 405 , which is sensitive between $345 \mathrm{~nm}$ and $460 \mathrm{~nm}$, including three dominate lines at $365 \mathrm{~nm}, 405 \mathrm{~nm}$ and $435 \mathrm{~nm}$. The $365 \mathrm{~nm}$ intensity is half the intensities at $405 \mathrm{~nm}$ and $435 \mathrm{~nm}$, hence the measured intensity at $405 \mathrm{~nm}$ was obtained by subtracting the intensities at $365 \mathrm{~nm}$ and $435 \mathrm{~nm}$. The exposure dose for mr-DWL $40 \mathrm{D}_{405}$ was optimized to obtain well resolved microstructures on the suspended layer (Figure 3.D).

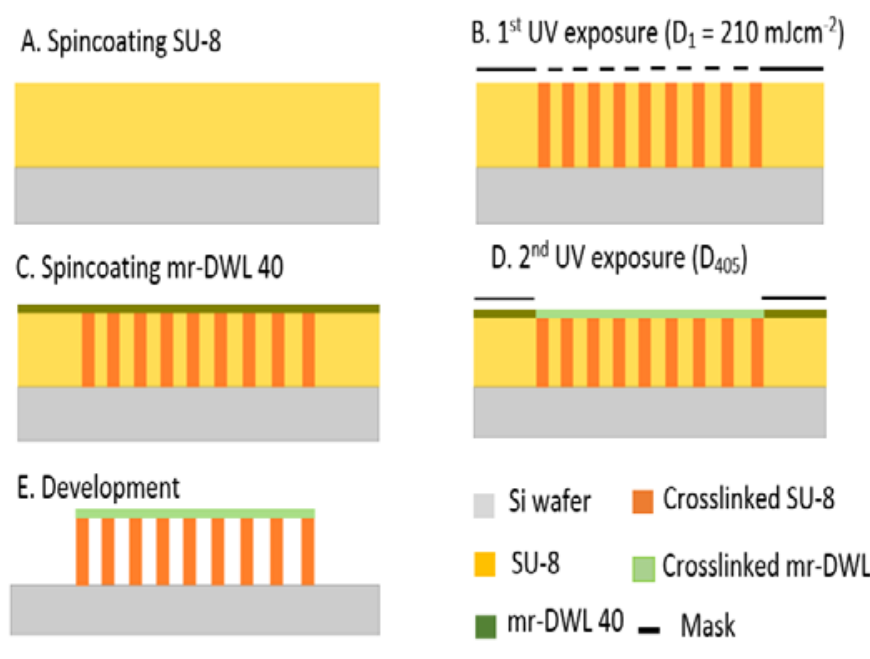

Figure 3 : Schematic of $405 \mathrm{~nm}$ microfabrication process: (A) SU-8 is spin coated on a $\mathrm{Si} / \mathrm{SiO}_{2}$ substrate and softbaked; (B) $1^{\text {st }}$ UV exposure at $365 \mathrm{~nm}$; (C) mr- DWL 40 spin coating on SU-8; (D) $2^{\text {nd }} U V$ exposure at $405 \mathrm{~nm}$ and postexposure-bake; (E) Development in PGMEA
This step was followed by a PEB at $50^{\circ} \mathrm{C}$ for $5 \mathrm{~h}$ and development in PGMEA in two steps of 10 mins each, rinsing in isopropanol for $30 \mathrm{~s}$ and drying in air (Figure 3. E).

\section{Results and discussion}

\section{1. $313 \mathrm{~nm}$ UV photolithography process}

For UV photolithography with $365 \mathrm{~nm}$ wavelength both the lateral dimensions and the thickness of the suspended layer have been difficult to control and reproduce. Here, a low wavelength $(313 \mathrm{~nm})$ was used to limit the cross-linking to the top surface. SU-8 absorbs considerably more UV radiation at wavelengths below $350 \mathrm{~nm}$ [8]. Therefore, activation of the photoinitiator in the bulk of the resist film is reduced and crosslinking can be limited to the top surface when using lower wavelengths for the partial exposure [8], [14].

We optimized a low temperature process to successfully fabricate suspended SU-8 layers with UV exposure at $313 \mathrm{~nm}$ wavelength for a large range of exposure doses $D_{313}$ (Figure 4). The UV exposure at $313 \mathrm{~nm}$ limited photoiniator activation to the top surface and allowed to reduce the thickness of the suspended layer (approximately $11 \mu \mathrm{m}$ ) compared to exposure at $365 \mathrm{~nm}$. However, the high absorption at $313 \mathrm{~nm}$ combined with diffusion of the photoinitator resulted in overexposure and complete crosslinking of the top surface without any patterns for an exposure dose $D_{313}=$ $10 \mathrm{mJcm}^{-2}$ (Figure 4. A). Even for a lower exposure dose of $5.25 \mathrm{~mJ} \mathrm{~m}^{-2}$ (5 s of UV exposure) the structures were still over exposed and no replication of the mask design $M_{2}$ was achieved (Figure 4.B). With an exposure dose of 

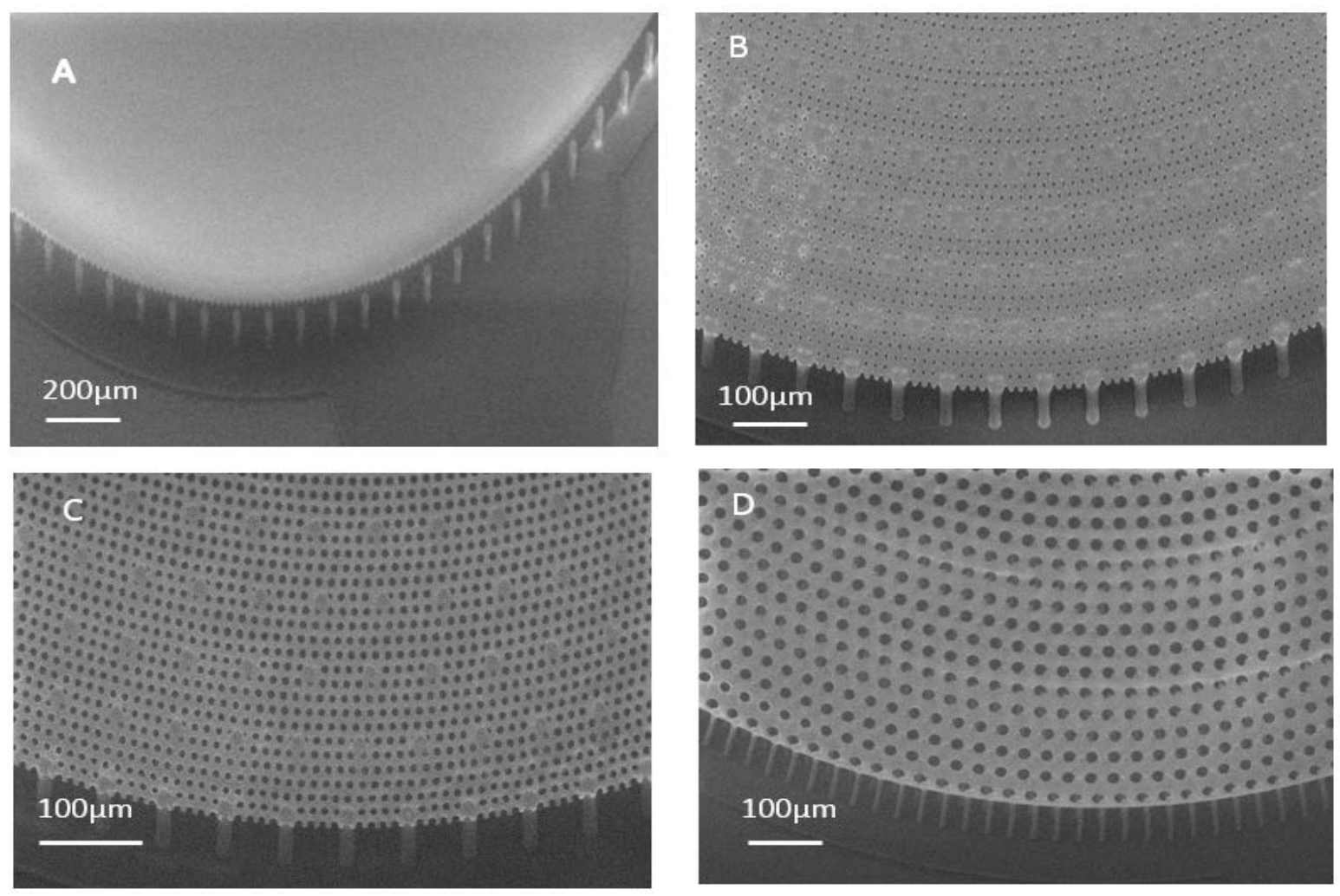

Figure 4: Second partial UV exposure optimization with $D_{313}$ (A) $10.50 \mathrm{mJcm}^{-2}$ (B) $5.25 \mathrm{mJcm}^{-2}$ and (C) and (D) $3.15 \mathrm{mJcm}^{-2}$

$3.15 \mathrm{mJcm}^{-2}$ ( $3 \mathrm{~s}$ of UV exposure) the patterns on $\mathrm{M}_{2}$ were replicated (Figure 4.C and D). The thickness of the suspended layer was approximately $11 \mu \mathrm{m}$ for all three exposure doses $\left(D_{313}\right)$. The holes with $10 \mu \mathrm{m}$ diameter and pitch $5 \mu \mathrm{m}$ was successfully fabricated on the suspended layer as showed in Figure 4.C. This demonstrates that the processing window for fabrication of suspended SU-8 structures with high lateral photolithographic resolution remains quite narrow when using UV exposure at $313 \mathrm{~nm}$. As a major drawback, it is not possible to control lateral resolution and thickness of the suspended layer independently, because both parameters depend on the exposure dose. This results in a less flexible process for fabricating patterned suspended layers with different thicknesses.

\section{2. $405 \mathrm{~nm}$ UV lithography process}

The limitation to control both lateral resolution and the suspended layer thickness precisely, lead us to explore a new fabrication process. The negative epoxy photoresist mr-DWL 40 has a photoinitiator which can be activated at $405 \mathrm{~nm}$. At the same time, SU-8 should not be crosslinked after UV exposure at $405 \mathrm{~nm}$ wavelength. First, the SU-8 crosslinking at $405 \mathrm{~nm}$ was evaluated by exposing $98 \mu \mathrm{m}$ thick SU-8 layers with an exposure dose of $220.5 \mathrm{mJcm}^{-2}$ (21 s of UV exposure). After development no SU-8 structures remained on the substrate. Next, the complete fabrication sequence illustrated in Figure 3 was performed. Figure 5 shows that suspended layers with a well-defined thickness of $17 \mu \mathrm{m}$ were obtained 

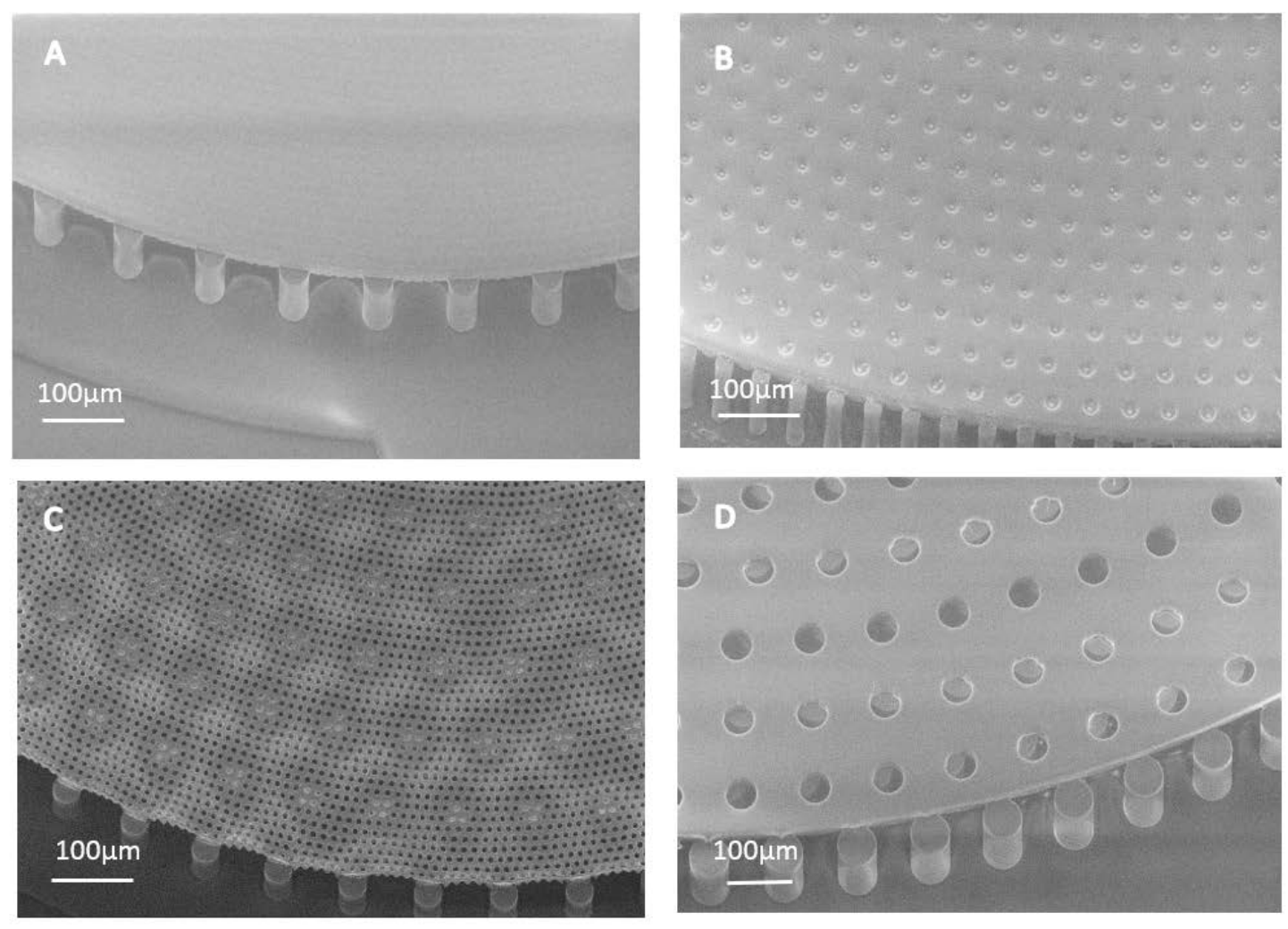

Figure 5: Second UV exposure $\mathrm{D}_{405}$ optimization (A) $105 \mathrm{mJcm}^{-2}$ (B) $52.5 \mathrm{mJcm}^{-2}$ (C) and (D) $31.50 \mathrm{mJcm}^{-2}$

for a large range of exposure dose $D_{405}$. Exposure doses of $105 \mathrm{mJcm}^{-2}$ (Figure $5 . \mathrm{A}$ ) and $52.5 \mathrm{mJcm}^{-2}$ (Figure 5.B) resulted in overexposure and the mask $\left(M_{2}\right)$ patterns were not replicated. For an exposure dose $D_{405}=$ $31.50 \mathrm{mJcm}^{-2}$ ( $3 \mathrm{~s}$ of UV exposure) well-defined suspended layers were fabricated.

With this fabrication process it is possible to define the pattern only in the $\mathrm{mr}$-DWL polymer (suspended layer) without affecting the supporting SU-8 structures. The thickness of the suspended layer is defined by a spin coating step and the lithographic resolution of the suspended layer is defined by the UV exposure dose at $405 \mathrm{~nm}$. This increases the processing window for patterning the suspended layer and allows independent tailoring of the two parameters.

\section{Conclusion}

Suspended SU-8 microstructures were fabricated with UV photolithography using two different wavelengths ( $313 \mathrm{~nm}$ and $405 \mathrm{~nm}$ ). For the process using $313 \mathrm{~nm}$, the optimized partial exposure dose $D_{313}=3.15 \mathrm{mJcm}^{-2}$ for a low temperature baking process was used to fabricate a well-defined suspended layer with $5 \mu \mathrm{m}$ suspended structures. This approach limited crosslinking to the top layer of the SU-8 film and increased the processing window for the exposure dose compared to earlier work performed with $365 \mathrm{~nm}$ [22]. However, simultaneous control of the thickness of the suspended microstructures was impossible. To achieve this, a novel process using UV lithography at $405 \mathrm{~nm}$ was optimized after spin coating a layer of a second epoxy based 
photoresist mr-DWL 40. The filtering of the lower wavelengths was achieved by simply inserting a PMMA sheet in a standard UV aligner. The optimized exposure dose for well resolved microstructures on a mechanically stable suspended layer of $\mathrm{mr}-\mathrm{DWL}$ was $D_{405}=31.50 \mathrm{mJcm}^{-2}$. In conclusion, a change in wavelength and the introduction of an additional spin coating step allowed optimal control of both thickness and lateral resolution and thereby improved processing flexibility. In future work, the suspended SU-8 structures will be used as a polymer template for C-MEMS to fabricate 3D carbon microelectrode.

\section{Acknowledgements}

The authors acknowledge funding by the Young Investigator Program of the Villum Foundation, project no. VKR023438.

\section{References}

[1] L. Jiang, M. Zhang, J. Li, W. Wen, and J. Qin, "Simple localization of nanofiber scaffolds via SU-8 photoresist and their use for parallel 3d cellular assays," Adv. Mater., vol. 24, no. 16, pp. 2191-2195, 2012.

[2] N. Ferrell, J. Woodard, and D. Hansford, "Fabrication of polymer microstructures for MEMS: sacrificial layer micromolding and patterned substrate micromolding," Biomed. Microdevices, vol. 9, no. 6, pp. 815-821, Oct. 2007.

[3] M. Aguirregabiria, M. Tijero, M. T. Arroyo, J. Elizalde, J. Berganzo, I. Aranburu, F. J. Blanco, and K. Mayora, "A new SU-8 process to integrate buried waveguides and sealed microchannels for a Lab-on-a-Chip," Sensors Actuators B Chem., vol. 114, pp. 542-551, 2006.

[4] P. Abgrall, C. Lattes, V. Conédéra, H. Sato, H. Matsumura, and S. Keino, "An all SU-8 microfluidic chip with built-in 3D fine microstructures," J. Micromechanics Microengineering, vol. 16, pp. 23182322, 2006.

[5] S. Tuomikoski and S. Franssila, "Freestanding SU-8 microfluidic chips by adhesive bonding and release etching," SENSORS ACTUATORS A Phys., vol. 120, pp. 408-415, 2005.

[6] P. Abgrall, C. Lattes, V. Conédéra, X. Dollat, S. Colin, and A. M. Gué, "A novel fabrication method of flexible and monolithic 3D microfluidic structures using lamination of SU-8 films," J. Micromechanics Microengineering, vol. 16, no. 1, pp. 113-121, Jan. 2006.

[7] R. Martinez-Duarte, "SU-8 Photolithography as a Toolbox for Carbon MEMS," Micromachines, vol. 5, no. 3, pp. 766-782, 2014.

[8] O. P. Parida and N. Bhat, "Characterization of optical properties of SU-8 and fabrication of optical components," ICOP 2009-International Conf. Opt. Photonics CSIO, p. PS3. E.8., 2009.

[9] A. del Campo and C. Greiner, "SU-8: a photoresist for high-aspect-ratio and 3D submicron lithography," J.

Micromechanics Microengineering, vol. 17, no. 6, pp. R81-R95, 2007.

[10] V. J. Cadarso, K. Pfeiffer, U. Ostrzinski, J. B. Bureau, G. a Racine, A. Voigt, G. Gruetzner, and J. Brugger, "Direct 
writing laser of high aspect ratio epoxy microstructures," J. Micromechanics Microengineering, vol. 21, no. 1, p. 17003, 2011.

[11] H. Sun and S. Kawata, Two-Photon Photopolymerization and 3D Lithographic Microfabrication. Springer US, 2004.

[12] Y. Ma, Y. Xia, J. Liu, S. Zhang, J. Shao, B. R. Lu, and Y. Chen, "Processing study of SU-8 pillar profiles with high aspect ratio by electron-beam lithography," Microelectron. Eng., vol. 149, no. January, pp. 141-144, 2016.

[13] Y. Lim, J.-I. Heo, and H. Shin, "Fabrication and application of a stacked carbon electrode set including a suspended mesh made of nanowires and a substrate-bound planar electrode toward for an electrochemical/biosensor platform," Sensors Actuators B Chem., vol. 192, no. 2014, pp. 796-803, 2014.

[14] F. Ceyssens and R. Puers, "Creating multi-layered structures with freestanding parts in SU-8," J. Micromechanics Microengineering, vol. 16, no. 6, pp. S19-S23, 2006.

[15] J. Melai, V. M. Blanco Carballo, C. Salm, and J. Schmitz, "Suspended membranes, cantilevers and beams using SU-8 foils," Microelectron. Eng., vol. 87, no. 5-8, pp. 1274-1277, 2010.

[16] P. Abgrall, S. Charlot, R. Fulcrand, L. Paul, A. Boukabache, and A. M. Gué, "Low-stress fabrication of 3D polymer free standing structures using lamination of photosensitive films," Microsyst. Technol., vol. 14, no. 8, pp. 1205-1214, 2008.
[17] C. Wang and M. Madou, "From MEMS to NEMS with carbon," Biosens.

Bioelectron., vol. 20, no. 10 SPEC. ISS., pp. 2181-2187, 2005.

[18] M. Kitsara, M. Chatzichristidi, D. Niakoula, D. Goustouridis, K. Beltsios, P. Argitis, and I. Raptis, "Layer-by-layer UV micromachining methodology of epoxy resist embedded microchannels," Microelectron. Eng., vol. 83, no. 4-9 SPEC. ISS., pp. 1298-1301, 2006.

[19] Y. Lim, J.-I. Heo, M. Madou, and H. Shin, "Monolithic carbon structures including suspended single nanowires and nanomeshes as a sensor platform," Nanoscale Res. Lett., vol. 8, p. 492, 2013.

[20] J. a Lee, S. W. Lee, K.-C. Lee, S. II Park, and S. S. Lee, "Fabrication and characterization of freestanding 3D carbon microstructures using multiexposures and resist pyrolysis," $J$. Micromechanics Microengineering, vol. 18, no. 3, p. 35012, 2008.

[21] M. Gaudet, J. C. Camart, L. Buchaillot, and S. Arscott, "Variation of absorption coefficient and determination of critical dose of SU-8 at 365 nm," Appl. Phys. Lett., vol. 88, no. 2, pp. 1-3, 2006.

[22] S.Hemanth, C.Caviglia, L. Amato, T. A. Anhøj, A.Heiskanen, J. Emnéus, and S. S. Keller, "Pyrolytic 3D Carbon Microelectrodes for Electrochemistry," in ECS Transactions, 2016, vol. 72, no. 1, pp. 117-124.

[23] S. Keller, G. Blagoi, M. Lillemose, D. Haefliger, and A. Boisen, "Processing of thin SU-8 films," J. Micromechanics Microengineering, vol. 18, p. 125020 , 2008. 
[24] T. A. Anhoj, A. M. Jorgensen, Z. D. A, and J. Hubner, "The effect of soft bake temperature on the polymerization of SU-8 photoresist," J. Micromechanics Microengineering, vol. 16, no. 9, pp. 1819-1824, Sep. 2006. 